\title{
Housing Choices and Preferences of Older Vacationers \\ In Southern China
}

\author{
Ambrose Ma, Ph.D. \\ and \\ Nelson W. S. Chow, Ph.D. \\ Department of Social Work and Social Administration \\ The University of Hong Kong \\ Room 1326, K.K. Leung Building \\ Pokfulam Road \\ Hong Kong
}

Tel: (852) 2859-2067

E-mail: amma@hkucc.hku.hk

December 2003 


\title{
The Housing Choices and Preferences of Older Vacationers
}

\author{
in Southern China
}

\begin{abstract}
Based on an existing dataset, this study examined the housing choices and preferences of Chinese elderly vacationers to the Pearl River Delta, and compared the effects of the personal attributes of the retiree and near-retiree vacationers on such preferences. Findings showed that the options, location and design of housing available in the market determined the housing preferences of these vacationers. The general housing preference patterns between the two groups of vacationers were similar to each other. However, their personal attributes had significant associations with their housing preference patterns. Implications on housing policies and further studies in related fields were discussed.
\end{abstract}

\section{KEY WORDS}

China, housing choices, housing preferences, retirees and near-retirees. 
Since Hong Kong’s reversion to Chinese sovereignty in 1997, increasing numbers of Hong Kong retirees have traveled to mainland China, where many near-retirees have already purchased vacation homes. A recent survey revealed that over 50,000 Hong Kong residents are living periodically on the mainland, with high concentrations in the Pearl River Delta (Hong Kong Census and Statistics Department, 2001). Another local survey estimated that approximately 22,000 elderly people aged 61 and over would move to Shenzhen, the most developed city in the Delta, within the next two years (Da Kung Pao, 2000). Indeed, a more recent study projects that increasing numbers of elderly residents will retire to the mainland in the coming twenty years (Hong Kong Census and Statistics Department, 2002).

Despite the increase in vacationing to the mainland by retirees and near-retirees in recent years, valid and reliable information about this new trend is scarce. A systematic and comprehensive study is needed to paint a complete picture of these older residents' vacationing, housing preference patterns and the implication on related policies.

\section{RELEVANT STUDIES}

Despite the large number of studies on elderly residential mobility, information on the housing choices and preferences of elderly vacationers has been meager. Of the existing studies, most focus on housing preferences and options (Gonyea et al., 1990; Hunt et al., 
2002; Madox, 1995; Malizia and Exline, 2000; Tripple et al., 1992; Zimmer and Chappell, 1997) that are related to residential movers or older persons in general, rather than elderly vacationers. Many of these studies investigate the effects of personal attributes such as marital status, age, income, occupation, class, and physical capacity on housing preferences or choices. Residential movers usually migrate to destination communities that can best satisfy their preference patterns which are largely determined by their socioeconomic characteristics (Clark et al., 1996; Walters, 2000 \& 2002). The movers’ affiliation with the destination communities is also affected by the age at which they move (Cuba and Hummon, 1993).

The availability of neighborhood amenities is the most important factor in housing suitability. The importance of these amenities is related to older residents' socio-demographic background, health status, residency, and social networks (Zimmer and Chappell, 1997). Of these amenities, items that are needed daily such as banks, food stores, a pharmacy, medical facilities, a library, and recreational facilities are considered most essential by retiree and near-retiree residents (Tripple et al., 1992; Zimmer and Chappell, 1997).

The housing preferences of individual consumers vary with their age. Younger households (aged 50 and under) are more likely to be concerned about spaciousness, low density, and pedestrian facilities, while older households prefer smaller lots and yards, and 
easy access to shopping areas and public transport (American LIVES, 1999; National Association of Home Builders, 1999).

In relocation, the personal attributes of older adults also strongly affect their decisions on various housing options. The elderly who have better resources prefer to move to continuing care retirement communities or condominiums, while the socially isolated and the economically vulnerable are more interested in moving to residential hotels or creating accessory apartments (Gonyea et al., 1990).

In Asian societies, many studies have investigated the housing issues that are related to older persons, but most concentrate on the relationship between housing and care for the elderly, living arrangements, or housing design and living environment. So far, no study has explored the housing choices and preferences of older vacationers. To fill the knowledge gap in the aforementioned areas, the investigators examine the housing choices and preference patterns of elderly Hong Kong residents moving to the Pearl River Delta of mainland China, and compare the effects of the personal attributes of the retiree and near-retiree movers on such preferences.

\section{RESEARCH METHOD}

This study is divided into two parts. The first part explores the housing options that are available to elderly Hong Kong residents vacationing to the Delta region. The 
investigators used key informant interviews and a content analysis of the promotional materials that were supplied by developers through various channels to estimate such options. The second part examines the housing choices and preferences of Hong Kong retiree and near-retiree vacationers, using as data a sub-sample from the Thematic Household Survey (THS) of the aspirations and experiences of Hong Kong people in taking up residence in mainland China (Hong Kong Census and Statistics Department, 2001).

The target population of the THS was all residents aged 18 and over in Hong Kong, and the sampling units were permanent quarters in built-up areas. Cluster random sampling method was used to select a sample. 24,320 individuals were successfully interviewed from April to June 2001 for a response rate of 75\%. The investigators extracted a sub-sample of 8,212 persons aged 50 and over from the original sample for the present study.

The dependent variable, housing preferences, was indicated by four constructs: the geographic location, type, interior size, and price or monthly rent of residential property. The investigator employed personal attributes as independent variables in this study. This variable referred to the interviewees’ age, gender, marital status, education level, personal monthly income, and employment status.

The investigators used two- and three-way cross-tabulations to examine the distributions of the indicators of the respondents' housing preferences in relation to their 
personal attributes. Chi-square tests assessed the associations between the indicators of housing preferences and the respondents' personal attributes. The use of Chi-square tests is appropriate in this study because most of the dependent and independent variables are of nominal scales.

\section{RESULTS}

In the following discussion, the investigators examine the available housing in the market and then analyses the respondents' housing choices and preference patterns.

\section{Housing Options for Older Vacationers}

Under the principle of “one country, two systems”, Hong Kong residents moving to mainland China are not eligible for permanent household registration, a situation similar to that of rural mainlanders who have migrated to the urban areas ( $\mathrm{Li}$ and Tang, 1998; Wu, 2002). However, Hong Kong vacationers are granted temporary household registration if they purchase a piece of real property from the developers there. These real properties are known as commodity housing, which has been tradable in the market since the housing reforms initiated by Deng Xiaoping in late 1978. The housing options for Hong Kong vacationers to the Pearl River Delta, in terms of location, type, size, and design are determined mainly by the available commodity housing built by the developers. The 
commodity housing that targets Hong Kong vacationers largely clusters in the cities/areas within a distance of between $33 \mathrm{~km}$ to $138 \mathrm{~km}$ from Hong Kong. This housing can generally be categorized into houses and condominium apartments, with a ratio of 2.8:7.2. The former includes single-family detached, semi-detached, and linked houses, while the latter is sub-divided into high-rise towers (from 6 to more than 12 floors) and low-rise buildings (from 4 to 6 floors). Approximately 92\% of the houses are medium sized (1500-2500 sq. ft.) or large (over 2500 sq. ft.). Most of them (75\%) are medium-priced, ranging from US $\$ 25.6$ per sq. ft. to US $\$ 76.8$ per sq. ft. In contrast, approximately $84 \%$ of the condominium apartments are of medium size (1000-1499 sq. ft) or small (under 1000 sq. ft.). Only 58\% are medium-priced and nearly $18 \%$ low-priced (under US\$25.6 per sq. ft.).

All of the commodity housing in the Delta is planned to target mature to old adults and their families, but none is aimed at retirees. In general, the developments in the east of the region tend to appeal to younger families with smaller children, while those in the west attract mature couples or older families. A few of the developments in the west also serve the needs of retiree investors by providing them with comprehensive medical facilities and healthcare, a tranquil environment, and healthy food.

\section{Housing Choices and Tenure}


In general, the surveyed vacationers preferred to live in residential buildings during their stay in mainland China. As shown in Table 1, however, more of the younger group favored staying in hotels (35.9\% vs. $27.8 \%$ ), while the older group was more likely to reside in residential buildings $(71.1 \%$ vs. $61.0 \%)$. This is not surprising, as the retiree respondents who had less personal income were more inclined to choose a cost-beneficial type of accommodation.

The results of Chi-square tests ( $p<.0001$ for both retirees and near-retirees) indicate that the housing choices of the surveyed retirees and near-retirees had a significant association with the tenure of their temporary abode. The most significant differences between these two groups of vacationers were their ownership of residential buildings and the free accommodation available to them. Specifically, more of the retiree (79.0\%) than the near-retiree respondents (76.1\%) stayed with their relatives or friends during their vacations, so their accommodation was free. This housing choice implies that the older group has a larger social network in the destination communities than does the younger group. As the younger respondents were better-off than the older respondents, more of the surveyed near-retirees (21.3\%) than the retirees (19.9\%) had purchased residential properties as second homes. This also suggests that the younger respondents have a more serious intention to travel to mainland China. 


\section{Relationship between Personal Attributes and Housing Preferences}

Because the results of Chi-square tests indicate that only marital status, education level, and personal monthly income were significantly associated with the indicators of housing preferences, the following discussion will concentrate on the relationship between these attributes and the housing preferences of the surveyed retiree and near-retiree vacationers.

General Housing Preferences

Both the surveyed retiree and near-retiree vacationers had similar housing preferences despite their age difference. The majority of these two groups of vacationers selected medium-sized (500-1499 sq. ft.) condominium apartments of a medium-price (US\$12,821-US\$38,460) mainly at Shenzhen, Dongguan and Guangzhou, the three most developed cities in the Delta region. These unexpected findings are contrary to those reported in previous studies that the housing preferences of the younger consumers are different from those of the older consumers (Clark et al., 1996; Malizia and Exline, 2000; Tripple et al., 1992; Walters, 2002). The possible reason for this phenomenon could be the limited housing choices available in the market. 


\section{Effect of Marital Status}

Similar to findings in previous studies, the marital status of the surveyed vacationers was found to have an effect on their housing preferences. As shown in Table 2, however, only the marital status of the retiree movers was significantly associated with the location $(p$-value $=.047)$, type $(p$-value $=.001)$, and size $(p$-value $=.033)$ of the residential properties that they owned or rented. In general, married and widowed/separated/divorced retiree movers favored small-medium or medium condominium apartments in the mostly developed cities of the Delta, such as Shenzhen, Dongguan, or Guangzhou. Surprisingly, the single retiree movers tended to select large houses located in Huizhou, a less developed city in the east of the Delta, and other areas in the provinces outside Guangdong. This could be explained by the lower prices or rents of residential properties in areas beyond the Pearl River Delta, which is the most developed region in China. The other reason could be that some of the unmarried older respondents intend to buy large houses as their marriage homes. It is an observable fact that, in recent years, a considerable number of elderly singles have gone to their hometowns to get married.

Despite the significant association of the retiree movers' marital status with their housing preferences, this relationship was not found in the younger group. This insignificant association could possibly be attributed to the relatively homogeneous marital status of the near-retiree vacationers, as a vast majority (80.7\%) of this group was married 
or cohabiting and only a minority was either widowed/separated/divorced $(12.6 \%)$ or single (6.7\%).

[Table 2 about here]

\section{Effect of Education Level}

The findings that are provided in Table 3 depict the relationship between education level and housing preferences. The education background of the surveyed near-retiree vacationers was significantly associated with both the location $(p$-value $=.004)$ and price ( $p$-value $=.007)$ of the residential properties they owned, but the education level of the retiree movers had an effect on the geographic location chosen only ( $p$-value $=.033$ ). Specifically, the near-retiree respondents who had received elementary or lower education were more likely to select medium- or high-priced residential properties in Shenzhen, Dongguan, and Guangzhou, while those with high school or higher education preferred low-end to medium-priced properties in various locations, including Shenzhen, Dongguan, Huizhou, and Jiangmem. Further analyses indicate that the main purpose of the less-educated respondents' temporary move to the Delta was to visit their relatives. To facilitate their frequent visits, they could be more willing to buy large, quality properties in areas close to their kinsmen and with convenient transportation. Although the highly-educated respondents also paid visits to their relatives, they valued traveling and 
sight-seeing more. Because they did not have fixed destinations for their vacations, they did not select high-priced properties as their second homes.

The effects of the retiree respondents' schooling on the preferred price of residential properties ( $p$-value $=.033)$ were similar to those of the younger group in that the highly-educated vacationers chose the low-end or medium-priced properties, while the less well-educated selected the medium-priced or high-end properties. However, their education background did not have a significant association with the location of their properties $(p$-value $=.252)$.

[Table 3 about here]

\section{Effect of Personal Income}

The results of association tests indicate that the respondents' housing preferences varied significantly with their personal income ( $p$-values $=.021$ for near-retirees and .032 for retirees). Table 4 displays the distribution of the income levels of both the retiree and near-retiree vacationers and their relationship with the preferred type of residential properties. A vast majority of the surveyed younger group (75.9\%-86.5\%) who had a high monthly income (US\$256 to over US\$2050) tended to select condominium apartments as their second homes. Unexpectedly, the low-income (under US\$256) near-retiree vacationers were more inclined to own or rent houses. The possible explanation for this 
finding could be that many of these vacationers intended to maintain ties with their kin, so they purchased large residential properties for family gatherings in the areas adjacent to their hometowns. In contrast, the higher-income group was more likely to vacation or work in the Delta region, and thus did not need large properties for accommodation.

The personal income of the surveyed retiree vacationers had different effects on their preferred type of residential properties. The majority of these vacationers (67\%-100\%) who were low-income earners (US\$2050 or under) chose condominium apartments, while a marginal majority (55.6\%) of the high-income (over US\$2050) retiree vacationers favored houses. This is understandable because the higher income group could afford to own houses which were generally more expensive than the apartments.

[Table 4 about here]

\section{DISCUSSION}

This study identified the housing choices and preferences of Hong Kong retiree and near-retiree vacationers to mainland China, and compared the effects of the personal attributes of these two groups on such preferences. The study found that almost none of the residential commodity housing built by the developers in the Pearl River Delta particularly targeted the surveyed movers. However, it is evident that the options, location, and design of housing available in the market are very similar to the respondents' housing preference 
patterns, which suggests that the available residential commodity housing largely determines the housing choices and preferences of Hong Kong retirees and near-retirees vacationing to the Delta. If there were more housing options in the market, then the housing preference patterns of the respondents would perhaps be very different from those reported here. To better understand the factors that affect retiree and near-retiree vacationers' housing preference patterns, future studies should examine various aspects of the housing stock that is available in the market, in addition to the personal attributes and life events of elderly vacationers.

The housing preference patterns of the surveyed retiree and near-retiree vacationers are very different from those of their counterparts in Western societies. In general, the elderly migrants in Western societies prefer single-family detached houses in suburban or other low density areas with auto-oriented neighborhoods and beautiful scenery. Many of them are also concerned about easy access to community amenities and facilities. In this study, however, the surveyed movers tended to select condominium apartments in age-integrated communities in highly urbanized areas where there were abundant recreational facilities, catering services, and convenient transportation networks. These different housing preference patterns are probably due to the limited housing options in the Pearl River Delta that were mentioned above, and could partly be a result of the respondents' experience of living in high-rise buildings in Hong Kong. Moreover, these 
can also be explained by the Chinese cultural attributes, such as the fact that Chinese people enjoy togetherness, closeness, and the bustle of life.

The findings of this study support those of previous studies in Western societies; namely, that the personal attributes of retiree and near-retiree vacationers have significant associations with various indicators of their housing preference patterns. Although the age difference of the two groups of respondents was not related to their housing preference patterns, the effects of their personal attributes varied significantly with the combinations of particular personal attributes and different age groups (aged 50-59 or aged 60+). These findings suggest that age difference per se may not be sufficient to affect the housing preference patterns of retiree and near-retiree vacationers, while marital status, education, and personal income could have stronger effects than other personal attributes such as physical capacity and health, especially in light of age differences. As no other personal attributes and indicators of housing preferences were available for analysis in the original data set, this speculation should be confirmed by further studies that include all other personal attributes and indicators.

Appropriate and affordable housing that can meet the housing needs of residents is essential in helping older persons to live decently and comfortably in the community. As residential vacationers usually select a living environment that can best satisfy their needs, their housing preference patterns reflect the characteristics of the housing that they desire. 
In designing housing for the Hong Kong retiree and near-retiree vacationers to the Delta, urban planners and housing developers should consider the effects of these vacationers' personal attributes on their housing preference patterns.

Although the housing preference patterns of these two groups are similar to each other, they are not homogeneous. It is worth noting that retirees are comprised of various sub-groups, ranging from 60 to 100 years of age. Their housing needs will vary with advancing age because of their declining physical capacity, deteriorating health, and changes in their living arrangements. To better serve the needs of the older retirees and to expand the existing target market, housing providers in private and non-government sectors should offer other housing options such as continuing care retirement communities or supportive housing to these movers. However, as elderly residents of Hong Kong are still unfamiliar with these new housing options, housing providers should market these housing products tactfully.

The above findings are based on a secondary analysis of an existing data set. Despite the data restrictions, the representative sample strengthens the external validity of the findings. The investigators believe that the findings of this paper will allow the formulation of positive policies on housing for retiree and near-retiree vacationers, and will provide inspiration for further studies in related fields. 


\section{REFERENCES}

American LIVES Inc. (1999). Community Preferences: What the Buyer Really Want in Design, Features and Amenities - A Follow-up Study to the 1994 Shopper and Home-owner Study and the 1995 New Urbanism Study, Oakland, C.A.

Clark, D.E., Knapp, T.A. and White, N.E. (1996). Personal and location-specific characteristics and elderly interstate migration. Growth and Change, 27:327-51.

Cuba, Lee and Hummon, David M. (1993). Constructing a sense of home: Place affiliation and migration across the life cycle. Sociological Forum, 8(4): 547-572.

Da Kung Pao (2000). “370,000 people will buy properties in Shenzhen within next two years,” a piece of news in a local Chinese newspaper, Hong Kong, 6 July 2000.

Gonyea, J.G., Hudson, R.B. \& Seltzer, G.B. (1990). Housing preferences of vulnerable elders in suburbia. Journal of Housing for the Elderly, 17(1):79-95.

Hong Kong Census and Statistics Department (2002). Hong Kong Population Projects 2002-2031. Hong Kong: The Hong Kong Special Administrative Region Government, China.

Hong Kong Census and Statistics Department (2001). Thematic Household Survey Report No. 7. Hong Kong: The Hong Kong Special Administrative Region Government, China.

Hunt, Michael E., Marshall, Linda J. and Merrill, John L. (2002). Rural areas that affect 
older migrants. Journal of Architectural and Planning Research, 19(1): 44-56

Li, Si-ming and Tang, Yin-ha (1998). Market segmentation and consumer characteristics of commodity housing in Guangzhou: An analysis of household survey data. Asian Geographer, 17(1-2): 69-89.

Maddox, George (1995). Housing choices for older person. Journal of Housing and Community Development, 52(4).

Malizia, Emil E., and Exline, Susan (2000). Consumer Preferences for Residential Developmental Alternatives, Working Paper 2000-02. University of North Carolina at Chapel Hill, Center for Urban and Regional Studies.

National Association of Home Builders (1999). 1999 Smart Growth Survey, Washington, D.C.

Tripple, P.A., McFadden, J.R., \& Makela, C.J. (1992). Housing environment important to retirement. Journal of Housing for the elderly, 10(2): 93-115.

Walters, William H. (2002). Place characteristics and later-life migration. Research on Aging, 24(2): 243-277.

Walters, William H. (2000). Assessing the impact of place characteristics on human migration: The importance of migrants' intentions and enabling attributes. Area, 32(1): 119-23. 
Wu, Weiping (2002). Migrant housing in urban China: Choices and constraint. Urban Affairs Review, 38(1): 90-119.

Zimmer, Zachary and Chappell, Neena (1997). Rural-Urban difference in seniors’ neighborhood

preferences. Journal of Housing for the Elderly, 12(1/2): 105-124. 


\section{Tables}

Table1: Age groups of Respondents, by Housing Choices, by Housing Tenure

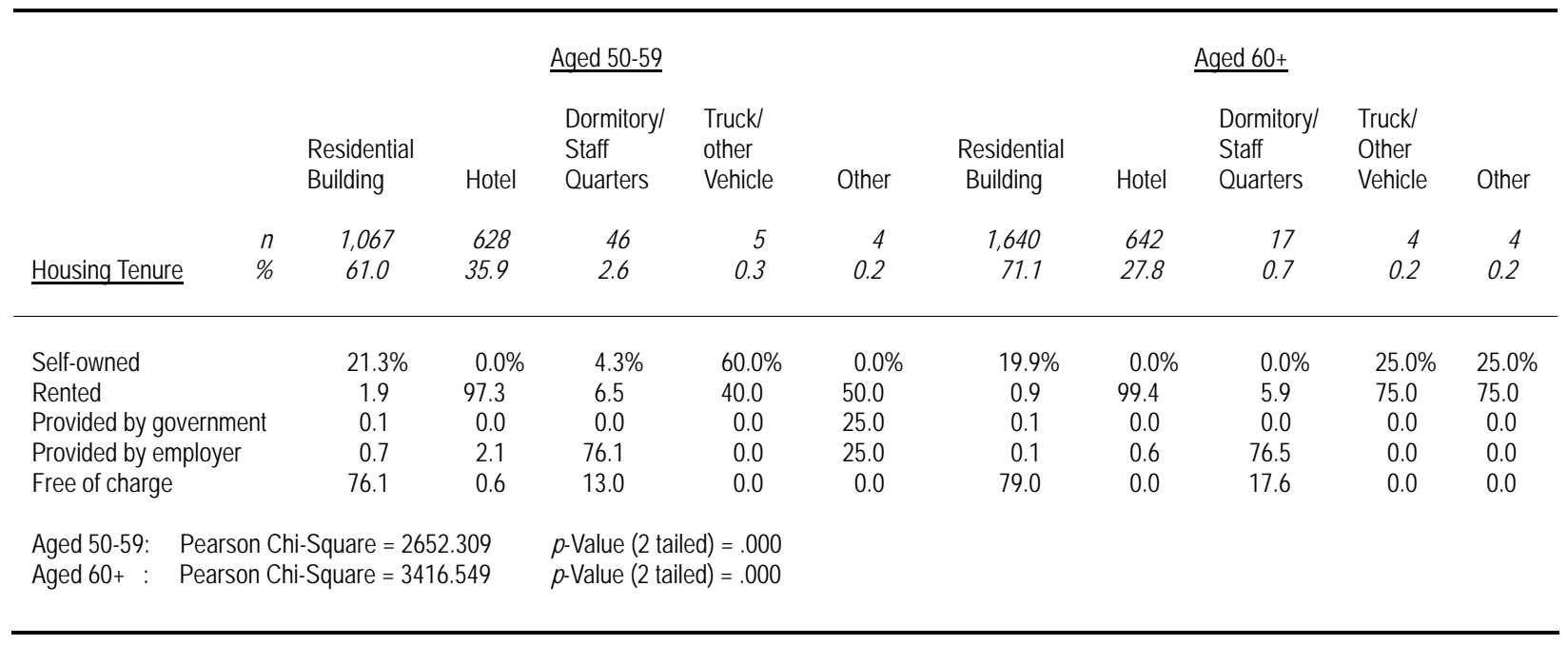


Table 2: Age Groups of Respondents, by Marital Status, by Indicators of Housing Preferences

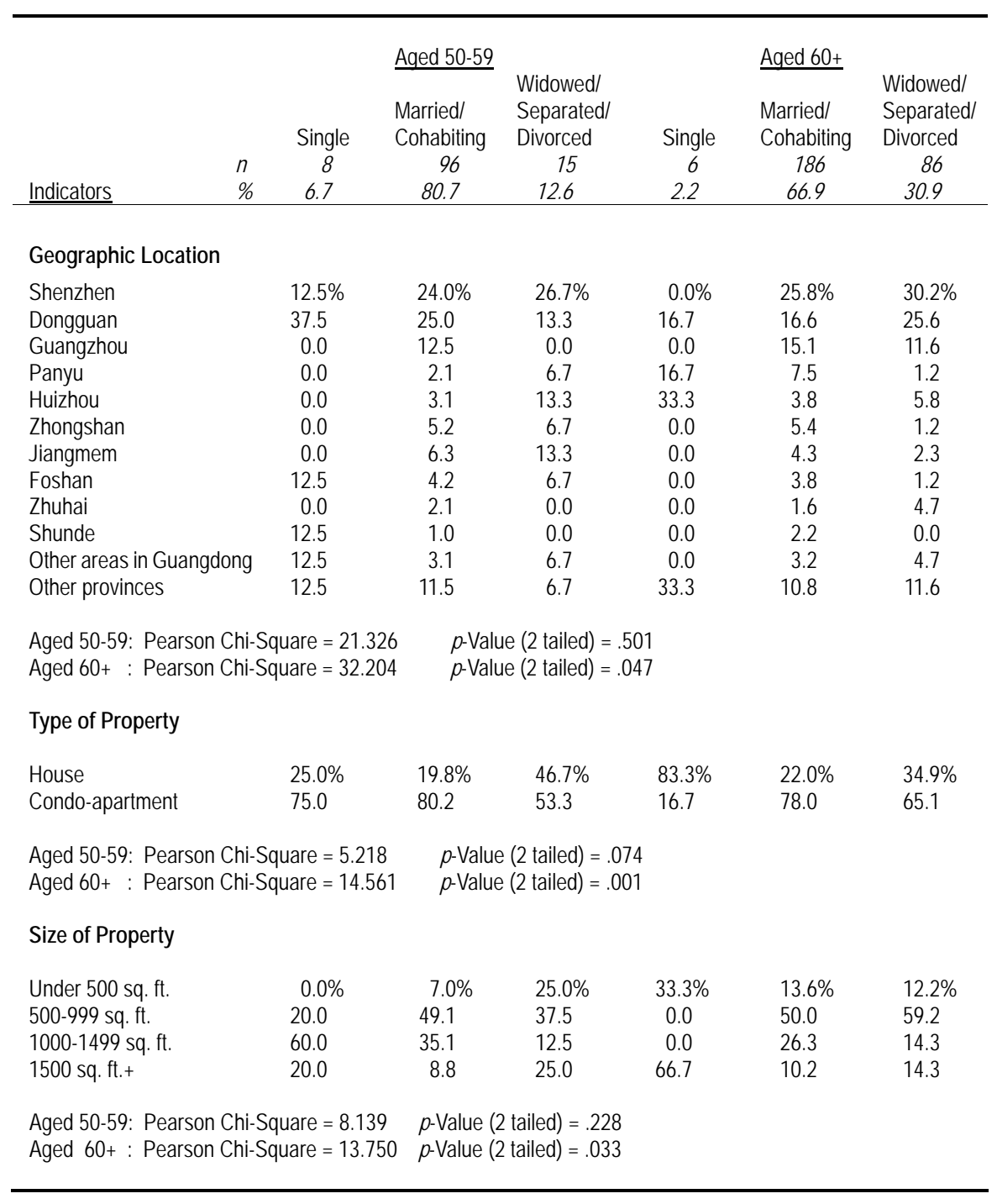


Table 3: Age Groups of Respondents, by Education Level, by Indicators of Housing Preferences

\begin{tabular}{|c|c|c|c|c|c|}
\hline & & \multicolumn{2}{|c|}{ Aged 50-59 } & \multicolumn{2}{|c|}{ Aged 60+ } \\
\hline & & $\begin{array}{l}\text { Elementary } \\
\text { or Lower }\end{array}$ & $\begin{array}{l}\text { High School } \\
\text { or Higher }\end{array}$ & $\begin{array}{l}\text { Elementary } \\
\text { or Lower }\end{array}$ & $\begin{array}{l}\text { High School } \\
\text { or Higher }\end{array}$ \\
\hline & $n$ & 68 & 51 & 222 & 56 \\
\hline \multicolumn{2}{|l|}{ Indicators } & 57.1 & 42.9 & 79.9 & 20.1 \\
\hline \multicolumn{6}{|c|}{ Geographic Location } \\
\hline \multicolumn{2}{|l|}{ Shenzhen } & $24.0 \%$ & $26.7 \%$ & $0.0 \%$ & $25.8 \%$ \\
\hline \multicolumn{2}{|l|}{ Dongguan } & 25.0 & 13.3 & 16.7 & 16.6 \\
\hline \multicolumn{2}{|l|}{ Guangzhou } & 12.5 & 0.0 & 0.0 & 15.1 \\
\hline \multicolumn{2}{|l|}{ Panyu } & 2.1 & 6.7 & 16.7 & 7.5 \\
\hline \multicolumn{2}{|l|}{ Huizhou } & 3.1 & 13.3 & 33.3 & 3.8 \\
\hline \multicolumn{2}{|l|}{ Zhongshan } & 5.2 & 6.7 & 0.0 & 5.4 \\
\hline \multicolumn{2}{|l|}{ Jiangmem } & 6.3 & 13.3 & 0.0 & 4.3 \\
\hline \multicolumn{2}{|l|}{ Foshan } & 4.2 & 6.7 & 0.0 & 3.8 \\
\hline \multicolumn{2}{|l|}{ Zhuhai } & 2.1 & 0.0 & 0.0 & 1.6 \\
\hline \multicolumn{2}{|c|}{ Shunde } & 1.0 & 0.0 & 0.0 & 2.2 \\
\hline \multicolumn{2}{|c|}{ Other areas in Guangdong } & 3.1 & 6.7 & 0.0 & 3.2 \\
\hline \multicolumn{2}{|c|}{ Other provinces } & 11.5 & 6.7 & 33.3 & 10.8 \\
\hline Aged 50-59: & \multicolumn{2}{|c|}{ Pearson Chi-Square $=27.148$} & \multicolumn{3}{|c|}{$p$-Value $(2$ tailed $)=.004$} \\
\hline Aged 60+ : & \multicolumn{2}{|c|}{ Pearson Chi-Square $=13.673$} & ue $(2$ tailed $)=$ & & \\
\hline \multicolumn{6}{|c|}{ Price of Property } \\
\hline \multicolumn{2}{|c|}{ Below $\$ 12,820^{\star}$} & $19.1 \%$ & $33.3 \%$ & $27.9 \%$ & $33.9 \%$ \\
\hline \multicolumn{2}{|c|}{$\$ 12,820-\$ 38,460$} & 33.8 & 47.1 & 36.0 & 48.2 \\
\hline \multicolumn{2}{|c|}{ Above $\$ 38,460$} & 47.1 & 19.6 & 36.0 & 17.9 \\
\hline \multirow{2}{*}{$\begin{array}{l}\text { Aged 50-59: } \\
\text { Aged } 60+:\end{array}$} & \multicolumn{2}{|c|}{ Pearson Chi-Square $=9.851$} & \multicolumn{3}{|c|}{$p$-Value $(2$ tailed $)=.007$} \\
\hline & \multicolumn{2}{|c|}{ Pearson Chi-Square $=6.841$} & \multicolumn{3}{|c|}{$p$-Value $(2$ tailed $)=.033$} \\
\hline
\end{tabular}

${ }^{*}$ Currency shown is US dollar 
Table 4: Age Groups of Respondents, by Personal Income, by Type of Residential Property

\begin{tabular}{|c|c|c|c|c|c|c|c|c|c|}
\hline & & \multicolumn{4}{|c|}{ Aged 50-59 } & \multicolumn{4}{|c|}{ Aged 60+ } \\
\hline & \multicolumn{2}{|r|}{ Under $\$ 256^{*}$} & \multirow{3}{*}{$\begin{array}{c}\$ 256-\$ 1153 \\
37 \\
40.7\end{array}$} & \multirow{3}{*}{$\begin{array}{r}\$ 1154-\$ 2050 \\
29 \\
31.9\end{array}$} & \multirow{3}{*}{$\begin{array}{r}\$ 2051+ \\
15 \\
16.5\end{array}$} & \multirow{3}{*}{$\begin{array}{c}\text { Under } \$ 256 \\
\qquad \begin{array}{c}113 \\
48.1\end{array}\end{array}$} & \multirow{3}{*}{$\begin{array}{c}\$ 256-\$ 1153 \\
106 \\
45.1\end{array}$} & \multirow{3}{*}{$\begin{array}{c}\$ 1154-\$ 2050 \\
7 \\
3.0\end{array}$} & \multirow{3}{*}{$\begin{array}{c}\$ 2051+ \\
9 \\
3.8\end{array}$} \\
\hline & $n$ & 10 & & & & & & & \\
\hline$\underline{\text { Type of Property }}$ & $\%$ & 11.0 & & & & & & & \\
\hline House & & $60.0 \%$ & $13.5 \%$ & $24.1 \%$ & $20.0 \%$ & $23.0 \%$ & $33.0 \%$ & $0.0 \%$ & $55.6 \%$ \\
\hline Condo-apartment & & 40.0 & 86.5 & 75.9 & 80.0 & 77.0 & 67.0 & 100.0 & 44.4 \\
\hline Aged 50-59: Pe & son C & i-Square $=9.6$ & $p-\mathrm{Va}$ & e $(2$ tailed $)=.02$ & & & & & \\
\hline Aged 60+: Pe & son C & i-Square $=8.8$ & $p-\mathrm{Va}$ & $\mathrm{e}(2$ tailed $)=.03$ & & & & & \\
\hline
\end{tabular}

* Currency shown is US dollar 